\title{
So you want to write a textbook?
}

\author{
Philip H Gordon MD FRCSC
}

J R Soc Med 2000;93:150-151

At some time in their lives many doctors have the urge to write a medical textbook but few ever realize their dream. The complexities of successfully completing a book are understood by few.

There are some myths about book-writing that might best be dispelled at the outset. The first is that, if you have written before, you can do it - it just takes time. This thought is but a delusion. Book-writing does indeed take time, and always much more than originally anticipated. It also demands dedication, perseverance, and yes, frustration. Having said that, there is much personal satisfaction to be derived from its completion. The process is well described by Apley': 'Writing is like having a baby; the gestation period is long and the labour painful, but in the end you have something to show for it'.

A second myth is that writing a book chapter is like writing a journal article, only longer. A journal article essentially describes highlights or focuses on a single point. A book chapter must develop an entire concept about a defined subject.

And a third myth is that book-writing will be highly profitable. In fact, the writing of a major textbook may well cost more, by taking the doctor away from his or her practice, than is gained from the subsequent royalties.

A very important point is the price paid by families. Spouses and children suffer days, weeks, months, and even years of 'absenteeism' by the author. The intentions may be honourable but the bottom-line is a sacrifice. Friends may likewise be victims, along with clinical practice and research projects.

So with this background, why would anyone want to write a book? The answers, of course, will vary from individual to individual. For a start, most people are unaware of the difficulty of the enterprise. Many truly believe they can assemble a body of information better than others have done. Some will be looking for fame or immortality, others (usually mistakenly) for financial security.

\section{PRELIMINARY CONSIDERATIONS}

Having decided (wisely or unwisely) that you want to write a book, you must find out whether there is any demand for

Sir Mortimer B Davis Jewish General Hospital, 3755 Cote Ste Catherine Road, Suite G 314, Montreal, Quebec H3T 1E2, Canada a work on your chosen subject. This may be a delicate issue and is best discussed first with trusted friends. Then talk with a publisher, who will often know what the market wants or will bear and will not be shy to tell you that the proposed book is not needed. Should you decide to pursue your dream, you must decide the depth and breadth of coverage and the format. Will it be a reference book or an atlas? You must also target your audience. Will you be writing for trainees or specialists? To write for all levels is impossible. Therefore, a publisher may ask for preliminary information such as a statement on the aims, scope and intended audience for the work, a tentative table of contents, an indication of the number of pages and illustrations and the schedule for completion.

A critical decision is the matter of authorship. Will the book be a solo effort? The decided advantage is that you work at your own pace and can organize the ideas and content exactly as you want. The down-side, of course, is that completion takes much longer and there is less opportunity for critical appraisal along the way. A second option is coauthorship with two or three others, one of whom will take charge of 'directing traffic'. Clearly, these colleagues should be carefully chosen to ensure compatibility, coherence, and uniformity of thinking. A track record of competence, cooperation and promptness are cardinal attributes. In this selection process strong personalities may emerge, and a common reason for failure is that one author is perceived not to be doing his or her fair share of the work. The third option is multiple authorship. The obvious advantage is speed, against which must be set lack of uniformity, different writing styles, overlap of content, and the fact that a chain is only as strong as its weakest link.

\section{SELECTION OF A PUBLISHER}

The first concern of an author may well be 'will anyone want me?' If you have not already written a book, you are unlikely to be pursued by a flurry of publishers begging for your manuscript. Prospective authors should therefore extract a commitment from a publisher before investing a lot of effort in the project. Established authors may be better-placed. Acquisition editors are very discerning professionals, and most are on the lookout for a quality book that will complement the 'stable' of their publishing house. Of paramount importance is the rapport that an 
author establishes with the senior medical editor or contact person. Some authors prefer to go with the largest publishing company possible, despite the risk of being 'lost in the shuffle'. An arrangement with a small publishing house may provide close personal contact with the key players but there may be doubt about its ability to produce and market the book to your satisfaction. After you have communicated with friends and colleagues, browsed through book exhibits at national meetings and conversed repeatedly with acquisition editors, the choice of publisher may well come down to personal chemistry - an important factor since these are the people you must deal with during the writing, editing, page proof and marketing stages. You should also try to protect yourself against the faint risk that after signing the contract you will never hear from the editor again. Satisfy yourself that your publisher has an understanding of your objectives and is in accord with them.

\section{NEGOTIATION}

What needs to be agreed from the start? I have already referred to length, audience and depth of coverage. Illustrations must be discussed because they are more expensive to produce than the written word. Although they can greatly enhance the product, some publishers discourage their inclusion. An agreement should be reached on the employment of black and white, half-tone, single or two colour, or full colour illustrations and the approximate number of each. A mixture of these is usually appropriate. Closely allied to the need for illustrations is the important matter of a medical illustrator. As with your coauthors and publisher you will be looking for competence and the right personal chemistry. You and the publisher must have an agreement on who bears the cost of the illustrator's work. Sometimes publishers offer a set sum or a percentage (e.g. $50 \%$ ) of the total cost, with the remaining part deducted from royalties. The book size, cover design, and quality of paper should be addressed.

Ask whether your publisher contemplates publishing anything else on the same subject. If there are two books, which will they promote? If they have some books that are related but not in direct competition with yours this can be a good thing, because publishers tend to cluster advertising; they will be keener to attend meetings and promote sales if they hope to sell more books than yours. Enquire about their promotional policy. Will they submit your book for book reviews? What meetings will they attend? Are they involved in personal selling? What journal advertisements do they plan? Do they prepare book bulletins, newsletters and annual catalogues? Do they have a direct-mail campaign and how vigorous will it be for your book? Will they make a special effort to attend meetings at which you or your coauthors are speaking? What is their policy on world-wide distribution and international marketing? Do your publishers have plans to attend international book fairs and will they seek opportunities to have your book translated into other languages. All these factors may be important in the overall success of the book.

Try to set a realistic completion date for your book. It will always take you longer than you think. Publishing is a business, and publishers only make money if there is a product to sell. Sometimes they push authors to the detriment of the product. They may, for example, wish the book to be ready for a major convention at which it could be launched. On the other hand, you will live to regret the publication of an inferior product solely for the sake of expediency.

The last and most sensitive issue is royalties. Although no publisher will accept a book without expecting to make a profit, you yourself should not expect to retire in the sun from the proceeds. Publishers often count on the pride and, yes, even the vanity of some authors in having them sign on the dotted line. Some publishing houses offer royalties as a percentage of the list price while others prefer to use the net price. The latter policy gives the publisher more flexibility in marketing, with deeper discounts to sell more books; if this option is chosen, then percentages negotiated should be higher than those based on list prices. Either way, royalties should escalate with rising numbers of books sold: typical plateaus are 0-3000, 3001-5000, 5001-10 000 . Lower rates are understandable with fewer books sold since the publisher must recover the production costs; however, there is no reason why the author should not fairly share in the profits.

In summary, writing a book almost always starts as a labour of love and ends up as an albatross around your neck, affecting everyone and everything around you. Winston Churchill put it well to his publisher on finishing a volume of war memoirs:

'Writing a book is an adventure. To begin with, it is a toy and an amusement; then it becomes a mistress, and then it becomes a master, and then a tyrant. The last phase is that just as you are about to be reconciled to your servitude, you kill the monster and fling him out to the public'.

\section{REFERENCE}

1 Apley AG. So you want to get published. J R Soc Med 1993;86:6-8 